\title{
Promoting Teaching Reform on Electronic Technical Basic Course, Taking National Undergraduate Electronic Design Contest
}

\author{
Wu Zuguo, Wang Jin, Ma Guosheng \\ College of Electronic Engineering, National University of Defense Technology
}

\begin{abstract}
This paper analyzes the main knowledge point involving national undergraduate electronic design contest, reviews the major feature of electronic technical basic courses in higher vocational colleges and proposes updated plan that closely combine electronic technical basic courses with undergraduate electronic design contest, which regards the teaching pattern of integration of theory and experiment as the main reform orientation and puts forward specific teaching design and organizational implementation methods, realizing the smart integration of teaching, learning and practicing so as to improve the practice ability and occupational quality of students.
\end{abstract}

Keywords-Undergraduate electronic design contest; Basic electronic technology; Teaching reform; Integration of theory and experiment

\section{INTRODUCTION}

Launched by the Ministry of Education, and Industry and Information Technology, national undergraduate electronic design contest is hosted by national undergraduate electronic design contest organizing committee. On the principle of closely combining real experience with the teaching and attaching great importance to the basic knowledge and the advanced application, the contest is aimed at promoting the discipline and course construction of electronics communication and leading institution of higher education to develop the innovative ability and cooperation spirit of undergraduate during teaching activity, increasing the construction of students' operational ability and practice on project, improving the students' comprehensive ability of making electronic design and production on practical problems, attracting and encouraging students to positively participate in the scientific activities after classes and creating the conditions for the excellent talent to serve the society.

The theme of this contest is dived into two sections, undergraduate and higher vocational students. The award is presented in different group respectively.

The theme of this contest includes "theory design" and "real production", based on application of circuit and digital cheater design and involving the application of analog-digital mixed circuits, single chip microcomputer and embedded system, PLD, DSP, EDA software.

Almost all the competition topics intend to have practical significance and application background. Considering the current teaching content and the application trends of new technologies, it will play a guiding role in the reform of teaching content and curriculum system and students' future work. It focuses on assessing the ability of participating university students to use basic knowledge to perform theoretical analysis and design, practical innovation and basic skills for independent work, and comprehensive skills for production and debugging. Meanwhile it encourages students to promote the human spirit of teamwork. The difficulty in competition topics should not only require the participating students to complete the basic requirements within the prescribed time, but also enable outstanding students to have full play and innovation. Through pre-competition training and participation in electronic design competitions, students' engineering design capabilities, engineering application capabilities and innovation capabilities can be effectively improved.

The National Undergraduate Electronic Design Contest adopts "one competition and two awards" and is divided into two types: "Regional Award" and "National Award". In order to encourage students to participate in this activity extensively, the general prize for the competition area is set up with first prize, second prize, third prize, successful competition prize and so on. After the evaluation of the competition area, the design report and relevant materials of the excellent competition team in the competition area shall be submitted to the national competition organizing committee. The national expert group shall pass the review, comprehensive evaluation and other evaluation links to select the national first and second prizes. Not more than $8 \%$ of the total number of actual national teams. For the same topic, the total number of the first and second prizes of the same school won no more than four, and the number of first-prize teams does not exceed two [1].

\section{THE CHARACTERISTIC OF ELECTRONIC TECHNICAL BASIC COURSE}

The "Electronic Technology Basics" course is a required course for specialists in electronic information and is a very important and practical professional basic course. Based on the pre-requisite "Electrical Basis", this course aims to enable students to master the basic knowledge of analog electronic circuits and digital electronic circuits and related practical skills, and lay the foundation for the follow-up professional courses. 


\section{A. Main teaching contents}

The main courses and knowledge of the "Electronic Technology Basics" course include the analysis and production of DC power supplies, analysis and production of low-frequency signal amplifiers, analysis and production of low-frequency signal generators, analysis and production of audio power amplifiers, and voting. Analysis and production of circuits, analysis and production of addition calculators, analysis and production of answering devices, analysis and production of timers, etc. There is a total of 120 hours of instruction in the class, of which 60 are theoretical lectures and 60 are practical teaching. Theoretical teaching and experimental teaching are interspersed and the integration of theoretical and experimental teaching is implemented.

\section{B. The basic characteristic of discipline}

The "Electronic Technology Basics" course is a study of various electronic circuits and components, and analyzes the characteristics of electrical signals after they are processed by various functional circuits. The electrical signal is very abstract, and it is something that neither can see nor touch, so learning the knowledge in this area is also more abstract. The electronic technology basic course has the characteristics of multiple components and models, multiple basic concepts, multiple circuit types, multiple analysis methods, and multiple signal classification. It has always been a lesson for teachers and students to fear. Teachers are not well organized and students are more difficult to learn and understand. At the same time, the foundation of college students is relatively weak, and most students are difficult to learn, analyze, and understand abstract knowledge. The traditional teaching mode of the "Electronic Technology Basics" course emphasizes theoretical teaching and light experimental teaching. Theoretical teaching and experimental teaching are often separated. For various reasons, the teaching effect of the "Basic Technology of Electronics" course is generally poor, and students' enthusiasm for participating in the National Undergraduate Electronic Design Competition is not high, and the results of the competition are even more difficult to satisfy. Therefore, we require that we must optimize the content of the lectures in the teaching process, pay attention to the combination of theoretical knowledge and experimental operations, guide students to learn, promote students to better understand theoretical knowledge, and use theoretical knowledge to solve practical problems.

\section{THE UPDATE OF COURSE CONTENTS}

To improve the teaching effect, we have based on the basic requirements and training objectives of the "Electronic Technology Basics" curriculum. Theoretically, we think that the basis for the follow-up courses is sufficient, and skill training and application practice are emphasized. Many common, practical electronic circuits that students are interested in, are easy to make, can be used for teaching demonstrations and students' hands-on practice are used for analysis, explanation and experimentation, highlighting the characteristics of vocational education in specialties and meeting the needs of engineering practice.
We integrated the teaching and experiment content of the "Basic Technology of Electronics" course into eight chapters for the analysis and production of DC power supplies. In the arrangement of the teaching content, we highlighted the direction of "enough and practical" teaching reform for all professional education courses It removes or avoids the usually cumbersome theoretical derivation process, and focuses on the application of integrated circuit devices according to the development of modern electronic technology In skills training and application practice, component identification and testing corresponding to teaching progress and teaching content, installation, testing and debugging of practical circuits are arranged. The optimized chapter teaching content mainly includes:

Analysis and production of DC power supply, including semiconductor basic knowledge, common diode testing and application, single-phase half-wave rectifier current, singlephase bridge rectifier circuit, filter circuit composition, performance analysis and test, diode voltage regulator circuit, Fixed output integrated voltage regulator device, adjustable output integrated voltage regulator device main performance indicators and applications [2].

Analysis and production of low-frequency signal amplifiers, including the transistor structure, type, main parameters, identification and detection, common emitter amplifier circuit and collector amplifier circuit (emitter output device) amplifier circuit composition, performance analysis and testing

Analysis and production of low frequency signal generators, including characteristics of ideal integrated operational amplifiers, voltage transfer characteristics, main parameters, linear applications and tests, basic concepts of negative feedback circuits, classification of feedback, discrimination of feedback types, negative feedback amplification circuits Block diagram and general expression, analysis and test of feedback circuit, basic concept of sine wave oscillator, analysis and test of RC sine wave oscillator

Audio power amplifier analysis and production, including power amplifier characteristics, classification, complementary symmetric power amplifiers, class B complementary symmetric power amplifier (OCL) composition, working principle, main performance and testing, commonly used integrated power amplifier performance, Selection and testing.

Voter analysis and production, including digital circuit characteristics, number system and coding, representation of arbitrary system number, conversion between arbitrary system numbers, logic operation, logic gate and skill training, logic function definition, logic function representation method, Skill training, standard forms of logic functions, logic functions, simplified formulas, Karnaugh diagram reduction and skill training, main performance parameters and skills training of TTL and CMOS integrated gate circuits.

Addition calculator analysis and production, including combinational logic circuit overview, analysis, design and skills training, encoder and decoder basic knowledge and skills training, data selector and data comparator basic 
knowledge and skills training, addition calculator Analysis, design and testing

Responder analysis and production, including basic RS trigger function analysis, description methods, basic RS trigger application and skills training, clock RS trigger, JK trigger, $\mathrm{D}$ trigger and $\mathrm{T}$ flip-flop analysis and testing, Responder circuit analysis, design and testing.

Analysis and production of timers, including counter classification, integrated synchronization counters, analysis and testing of asynchronous integrated counters, implementation and application of arbitrary binary counters, concepts of registers and shift registers, analysis and application of commonly used integrated register devices, Practical timing circuit design and testing.

\section{THE ORGANIZATION AND IMPLEMENTATION}

To mobilize the enthusiasm of students and improve teaching effectiveness, we changed the previous model of imparting pure theory during the teaching of the "Basic Technology of Electronics" course, and more of it is to combine theoretical knowledge and practical operation with each other. The teaching model integrated with the experiment is used to deepen students' understanding of knowledge points.

In the integration of theory and experiment teaching, the teaching is not based on teachers but students. The teacher provides the students with an excellent learning environment, and then instructs the students to solve the problems and learn knowledge in the process of solving problems. While accumulating experience and lessons. Teaching is conducted in a laboratory that satisfies the integration of theoretical and experimental teaching conditions. It is no longer a matter of distinguishing between theoretical and practical courses. It is experimental in theory and theory in experiments. In the teaching project, teacher's teaching, student's learning and doing are interspersed with each other flexibly [3].

In the teaching process, the teacher first demonstrates a circuit with practical functions, so that students can hear the sound, see the waveform of the signal through the instrument, see the actual effect, and mobilize the students' enthusiasm for learning. Then let the students manually install and solder the circuit according to the schematic diagram and observe the experimental phenomenon. After the problem occurs, the teacher can promptly answer questions and solve the problem. In the guidance and answering questions, teachers actively guide students to think and let students think about what knowledge they have used. Some questions why we cannot explain it now? After the circuit is debugged, the teacher summarizes the theoretical knowledge of the actual circuit just as the example is combined to do systematic analysis and explanation. By combining theory and experiment effectively, the boring theory is put into interesting practical training. It realizes how teachers "teach", how students "learn" and how to "do" the perfect unity so that students are full of each lesson. Self-confidence, I feel that I can not only make physical objects, but also have a complete understanding of the working principle of the actual circuit, but also can analyze and eliminate the fault phenomenon of the circuit from the perspective of theoretical knowledge, greatly stimulating students' interest in learning. From the original "I want to learn" to "I want to learn" [4].

In the following, taking "Electronic Technology Fundamentals" as an example, we will introduce the implementation of the theoretical and experimental integrated teaching of "Analysis and Production of Audio Power Amplifiers".

The first step: Instruct students to start installing and debugging the OCL audio power amplifier according to the given circuit diagram. Give a typical audio power amplifier, probably analyze the working principle of the circuit, the role of the main components, guide students in the circuit board installation, welding test circuit.

Step 2: Instruct the students to check the basic functions of the installation circuit for the first time. If there is any failure, they will not be solved temporarily. Switch on the power supply and the input audio input signal, and the speaker at the output end of the power amplifier will output the audio signal, indicating that the function of the circuit is basically normal. Respectively change the input signal amplitude, frequency and other parameters, observe the speaker output audio signal changes. Introduced audio power amplifier output power, frequency characteristics, signal distortion and other issues.

Step 3: Analyze the working principle of the OCL audio power amplifier output stage circuit. In the static push-pull circuit, the two transistors are not biased by DC and are in Class B operation. In the dynamic state, when the input is a positive or negative half cycle of a sinusoidal signal, two transistors in the push-pull circuit are turned on in turn, and a complete sinusoidal signal is obtained at both ends of the load speaker. Then derive the formula for the output power and conversion efficiency of the OCL audio power amplifier. Then analyze the maximum tube consumption of the two transistors in the push-pull circuit, the distortion phenomenon of the output signal and the measures to eliminate the crossover distortion.

Step 4: Instruct the students to measure the performance indicators such as the quiescent operating point, maximum output power, efficiency, and frequency characteristics of the OCL audio power amplifiers they have installed, and observe the phenomenon of crossover distortion. Change the DC power supply voltage, load impedance, input signal frequency, etc., observe the changes in the main performance indicators of the amplifier.

Step 5: Instruct students how to judge the cause of the circuit failure based on the test performance indicators.

Step 6: the course summary, according to theoretical analysis, experimental measurement, etc. summarize the main performance of the OCL audio power amplifier, there are deficiencies, the introduction of other power amplifier circuit.

Through the integration of theoretical and experimental teaching modes in the "Electronic Technology Basics" curriculum, students' interest in learning and practical handson skills can be improved 


\section{CONTACT ELECTRONIC DESIGN COMPETITION TO ARRANGE COMPREHENSIVE TRAINING PROJECT}

Although we have adopted a teaching model integrating theory and experiment in the teaching of each lesson, students' understanding of theoretical knowledge and mastering of engineering practice skills have been improved, but it is not enough to achieve comprehensive application of learned knowledgePro. Therefore, at the end of each chapter, we combined the topics of electronic design competition and arranged a comprehensive design small project. The teacher instructs the students to use the theoretical knowledge they have learned and to analyze the design scheme of the competition title. Students use the spare time to design and install several comprehensive design projects for selection at the end of the course.

The following is an example of the H-title (LED flash power supply) of the 2015 National Undergraduate Electronic Design Contest Senior Vocational Training Group, which shows how to combine the electronic design

Competition with the teaching of the "Electronic Technology Basics" course.

The task of designing the game is to design and make an LED flash power supply. The core of the power supply is a DC-DC stabilized current power converter, which converts the battery's power into a constant current output and drives highbrightness white LEDs. The power supply has two modes of continuous output and pulse output, with output voltage limiting protection and alarm function.

The core of the game is a DC-DC steady current converter, which can convert the power of a 3.0 to $3.6 \mathrm{~V}$ DC voltage source into a constant current output to drive high-brightness white LEDs. The power supply has both boost and constant current functions. The step-up part is realized by the DC-DC conversion technology. The boosted DC power supply passes through the constant current control circuit, and the output current is adjustable in size. The whole circuit has two output modes, one continuous output mode, one pulse output mode, the current size can be set to different control positions, the load resistance becomes larger, and there is overvoltage protection when the output voltage is higher than the set value.
Alarm function. The output current of $200 \mathrm{~mA}$ and the output voltage of $10 \mathrm{~V}$ should be higher than $80 \%$.

There is a lot of knowledge involved in the competition and it is not possible to use a certain chapter to complete the knowledge. Therefore, we divide the topic into several small training projects in the teaching process, complete different small projects in different chapters, and finish all the contents. After finishing all the completed small projects together, the design task can be completed. The individual content of this course may not be involved. We directly provide a reference circuit to allow students to gradually grasp [5] in the follow-up course.

\section{CONCLUSION}

The electronic technology basic course is closely integrated with the electronic design of university students. The integration of theoretical and experimental teaching is an effective teaching method. The abstract and boring theoretical knowledge is verified by vivid and interesting experimental processes, enriching the contents of classroom teaching and practical teaching. Students learn how to learn and learn how to use it in practice. This will help students improve their practical ability and gain better teaching results within a limited number of hours. In the fall of 2016 , the first time we organized the implementation of electronic technology basic theory and experimental integration teaching college students to participate in the Anhui University students electronic design competition, won the second prize of the specialist group of good results.

\section{REFERENCES}

[1] www.nuedc.com.cn(the official website of national undergraduate electronic design contest)

[2] Lulu. Research on Curriculum Reform of Higher Vocational Analog Electronic Technology. Health Vocational Education,2013(05)

[3] Liu Hongren. Build an integrated platform and Optimize digital logic teaching. Technology style,2010(11)

[4] Song Dongya, Zhu Xinjian. Exploring the Integrated Teaching Mode of Digital Electronic Technology Curriculum. Electronic test, 2013(24)

[5] Chen Rongfu, Li Jianbo. A LED flash power design. Science and Technology Economic Guide, 2016(1) 